University of Vermont

UVM ScholarWorks

$10-1-2017$

\title{
Isolation by distance, not rivers, control the distribution of termite species in the Amazonian rain forest
}

\author{
Cristian S. Dambros \\ University of Vermont \\ José W. Morais \\ Instituto Nacional de Pesquisas Da Amazonia \\ Renato A. Azevedo \\ Instituto Nacional de Pesquisas Da Amazonia \\ Nicholas J. Gotelli \\ University of Vermont
}

Follow this and additional works at: https://scholarworks.uvm.edu/casfac

Part of the Climate Commons

\section{Recommended Citation}

Dambros CS, Morais JW, Azevedo RA, Gotelli NJ. Isolation by distance, not rivers, control the distribution of termite species in the Amazonian rain forest. Ecography. 2017 Oct;40(10):1242-50.

This Article is brought to you for free and open access by the College of Arts and Sciences at UVM ScholarWorks. It has been accepted for inclusion in College of Arts and Sciences Faculty Publications by an authorized administrator of UVM ScholarWorks. For more information, please contact scholarworks@uvm.edu. 


\title{
Isolation by distance, not rivers, control the distribution of termite species in the Amazonian rain forest
}

\author{
Cristian S. Dambros, José W. Morais, Renato A. Azevedo and Nicholas J. Gotelli \\ C. S. Dambros (csdambros@gmail.com) and N. J. Gotelli, Dept of Biology, Univ. of Vermont, Burlington, VT, USA. - J. W. Morais and \\ R. A. Azevedo, Coordenação de Pesquisas em Biodiversidade, National Inst. of Amazonian Research, Manaus, AM, Brasil.
}

\begin{abstract}
The spatial distribution of species is affected by dispersal barriers, local environmental conditions and climate. However, the effect of species dispersal and their adaptation to the environment across geographic scales is poorly understood. To investigate the distribution of species from local to broad geographic scales, we sampled termites in 198 transects distributed in 13 sampling grids in the Brazilian Amazonian forest. The sampling grids encompassed an area of $271500 \mathrm{~km}^{2}$ and included the five major biogeographic regions delimited by Amazonian rivers. Environmental data for each transect were obtained from local measurements and remote sensing. Similar to previous studies, termite species composition at the local scale was mostly associated with measures of soil texture and chemistry. In contrast, termite species composition at broad geographic scales was associated with soil nutrients, and the geographic position of the transects. Between 17 and $30 \%$ of the variance in termite species composition could be attributed exclusively to the geographic position of the transects, but could not be attributed to measured environmental variables or the presence of major rivers. Isolation by distance may have strong effects on termite species composition due to historic processes and the spatially structured environments along distinct geological formations of Amazonia. However, in contrast to many taxa in Amazonia, there is no evidence that major rivers are important barriers to termite dispersal.
\end{abstract}

The spatial distribution of species is affected by geographical barriers to dispersal, by the environment, and by the presence of competitors and predators. At large geographic scales, dispersal limitation is likely to affect the distribution of species with low dispersal capacity (Cadotte 2006, Thompson and Townsend 2006). In contrast, at small geographic scales species are less limited by dispersal, and show stronger associations with biotic and abiotic conditions than with geographic isolation (Hurtt and Pacala 1995, Hubbell 2005). Despite the importance of both dispersal limitation and the environment to species richness and species composition (Leibold et al. 2004, Cadotte 2006), few studies in Amazonia have attempted to determine their effects on species distribution at broad and local geographic scales.

In Amazonia, the distribution of vertebrates has been associated with the presence of geographical barriers to dispersal, such as large rivers (Ribas et al. 2011, Pomara et al. 2014, Boubli et al. 2015, Dias-Terceiro et al. 2015). However, other taxa with higher dispersal ability, such as plants (Tuomisto et al. 2003, Kristiansen et al. 2012, Pomara et al. 2014) and many insects (Penz et al. 2015), are unlikely to be limited in their dispersal by rivers. These taxa should be more strongly associated with local environmental conditions than with geographic distance or the presence of barriers.

Several studies of Amazonian plants (Tuomisto et al. 2003, Costa 2006, Kristiansen et al. 2012) and animals
(Menin et al. 2007, Tarli et al. 2014) have found that the similarity in species composition between sites is correlated with differences in soil texture and chemistry. However, most of these studies are conducted at relatively small spatial scales, and do not encompass multiple geological formations or the major rivers of Amazonia. Therefore, it is not known if results obtained at local spatial scales can explain the distribution of species at broad spatial scales. Recent studies found that the distribution of palm trees is strongly associated with soil texture at local spatial scales (Costa et al. 2009), whereas soil chemistry (Tuomisto et al. 2003, 2014, Higgins et al. 2011, Kristiansen et al. 2012) and isolation by distance (Eiserhardt et al. 2011) are more important at broad scales. However, no single study was able to associate the distribution of species with geography and environmental conditions across multiple scales, and to demonstrate in which scale niche and neutral processes are more important for species distribution.

In this study, we measured at local and broad geographic scales how termite species richness and composition are associated with spatial predictors, the presence of rivers, and measures of climate, tree cover, soil texture, and soil chemistry. We hypothesized that local environmental conditions, such as soil clay content, would be strongly associated with changes in termite species composition at local geographic scales, whereas space, riverine barriers, and 
climate would be associated with changes in species composition at broad geographic scales.

Termites are among the most abundant animals in tropical forests (Fittkau and Klinge 1973). Termite species can be strongly associated with climate at broad geographic scales (Cancello et al. 2014), and with edaphic conditions and vegetation at local scales (Davies et al. 2003, Roisin and Leponce 2004). However, in contrast to many vertebrate taxa studied in Amazonia, reproductives of termite species can form large swarms and disperse very long distances (Wilfert et al. 2006). Over the past $52 \mathrm{Ma}$, termite lineages have dispersed multiple times across continents followed by in situ diversification (Bourguignon et al. 2014). Despite the transcontinental distribution of several termite genera (Bourguignon et al. 2014), termites are mostly restricted to tropical forests (Bignell et al. 2011), and climate is likely to play an important role in their distribution at broad scales.

\section{Material and methods}

\section{Study area}

The area of termite sampling encompassed an extent of $271500 \mathrm{~km}^{2}$ of the Brazilian Amazonian rainforest (Fig. 1), and included three climate types: Tropical Rainforest Climate (Af), Tropical Monson Climate (Am), and Tropical Savanna Climate (Aw; Peel et al. 2007). The study area covers a gradient in annual precipitation from $\sim 1800 \mathrm{~mm}$ in the southern and the northern areas to $\sim 2000 \mathrm{~mm}$ in central areas. The vegetation in the field sites is predominantly characterized by dense evergreen forests, but also includes savannas, campinaranas (open forests), and small areas of lowland forests subject to periodical flooding ( $<5 \%$ of total).
Elevation ranged from 32 to $145 \mathrm{~m}$ a.s.l. (mean $=84$ ), and soil clay content ranged from $<0.5$ to $87 \%$ (mean $=34 \%$ ).

\section{Sampling design and data collection}

Termites were sampled between December 2008 and September 2014 in $199250 \mathrm{~m}$ long transects (sampling units) grouped in 13 regular grids (Fig. 1). Grids and transects were previously established by the Long Term Ecological Research project aiming at the collection and comparison of multiple taxa (Magnusson et al. 2005). Each grid had from five to 31 transects. Transects were separated by at least $1 \mathrm{~km}$ from one another, and followed an elevation isocline to minimize variation in edaphic conditions within each transect. Transects were established at least $10 \mathrm{~m}$ away from the nearest walking trail. One transect was flooded during sampling, but termites were not found on tree tops above the water level, so we removed the transect from analyses $(n=198)$.

Along the central line of each transect, five equally-spaced $5 \times 2 \mathrm{~m}$ sections were surveyed for termites (modified from Jones and Eggleton 2000). In 60 transects, five additional sections per transect were surveyed, and in 28 transects, seven additional sections were surveyed, for a total of 1486 sections surveyed. In each section, three investigators searched for termites for $20 \mathrm{~min}$, yielding $1 \mathrm{~h}$ of sampling per section, and a total of $1486 \mathrm{~h}$ of sampling for the entire study. Each section was thoroughly searched for termites in the soil, fallen logs, small branches, standing trees, and nests. Nests in trees above $2 \mathrm{~m}$ were not surveyed. The number of transects and sections sampled within each transect were defined to maximize the power of the statistical tests used in this study (Supplementary material Appendix 1, Text A1, Fig. A1).

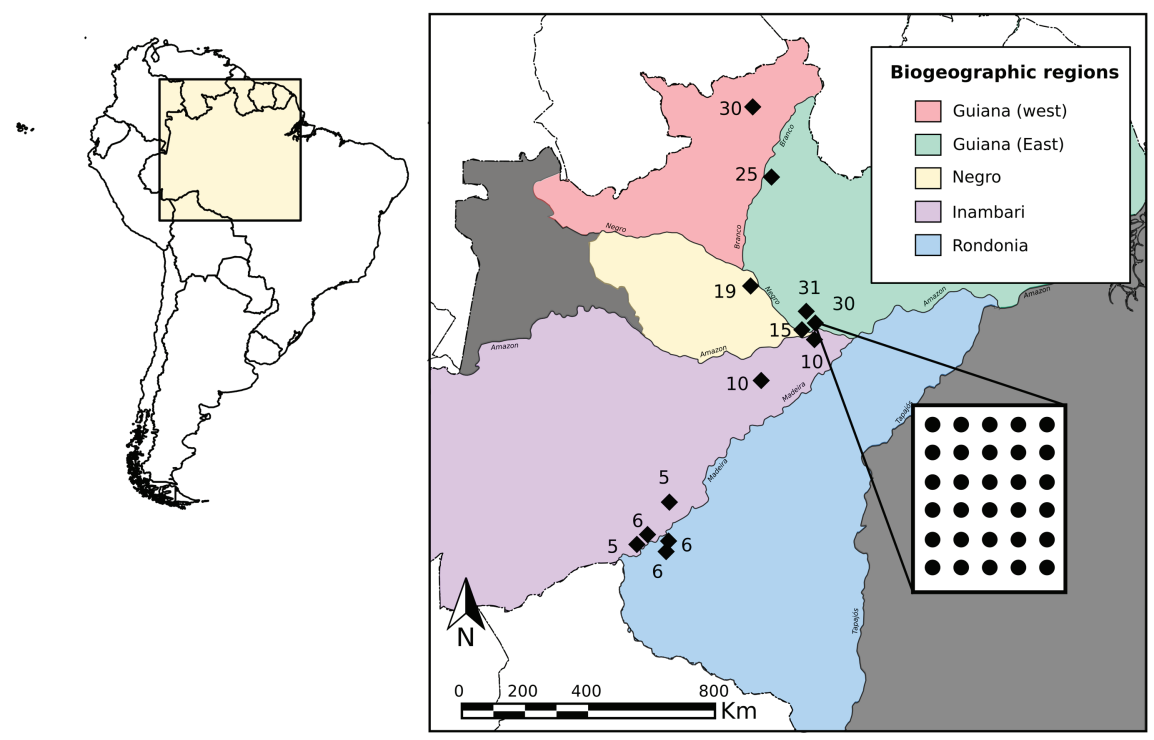

Figure 1. Location of sampling grids and transects (black circles) in the Brazilian Amazonian forest. Colors represent distinct biogeographic regions delimited by the major rivers in the Amazonian forest previously associated with the distribution of several vertebrate taxa (Ribas et al. 2011, Pomara et al. 2014, Boubli et al. 2015, Dias-Terceiro et al. 2015). Numbers represent the number of transects sampled in individual grids. Five $5 \times 2 \mathrm{~m}$ sections were sampled in each transect. Grey areas represent biogeographic regions within Brazilian Amazonia not surveyed in our study. 
Termite soldiers and workers were hand-collected and stored in $4 \mathrm{ml}$ containers filled with $95 \% \mathrm{EtOH}$. Voucher specimens of all species are deposited in the Entomological Collection of the National Inst. of Amazonian Research (INPA), Manaus, Brazil. Termites were sorted to genus following Constantino (1999), and then to species or morphospecies by comparison with species descriptions and material deposited in the Entomological Collection of INPA.

We assigned each termite species to one of three feeding guilds following Donovan et al. (2001), Davies et al. (2002) and Davies et al. (2003): wood feeders, soil feeders, or leaf-litter feeders. Termite species richness and composition were analyzed as a whole, and separately for wood and soil feeding termites. Leaf-litter feeders comprised a small fraction of species, and were not analyzed separately from other groups.

At the transect level, we analyzed termite community structure with predictor variables of mean annual temperature, mean annual precipitation, altitude, tree cover, soil clay content, and soil nutrients of $\mathrm{P}, \mathrm{Ca}^{2+}, \mathrm{K}^{+}$, and $\mathrm{Mg}^{2+}$. Mean annual temperature and precipitation were obtained at the 0.5 arc min resolution $(\sim 1 \mathrm{~km})$ from bioclim (Hijmans et al. 2005). Other climatic variables available in bioclim, such as monthly average temperature and precipitation, are correlated with mean annual temperature and precipitation, and were not included in our analyses.

Altitude data for each transect were obtained in $90 \mathrm{~m}$ resolution rasters from The Global Land Survey Digital Elevation Model (GLSDEM; USGS 2008), provided by The Global Land Cover Facility (GLCF), Univ. of Maryland (<www.landcover.org $>$ ). In the study region, altitude data originated primarily from images from the Shuttle Radar Topographic Mission (SRTM; NSF OpenTopography Facility 2013). Altitude data obtained from remote sensing were strongly correlated with in situ measurements obtained from a GPS device placed along the central line of each transect $(r=0.89 ; n=90)$. Because SRTM data were available for all our transects, only SRTM data were used in our models. Percentage of tree cover was also obtained from GLCF at a $30 \mathrm{~m}$ resolution scale (Sexton et al. 2013). Tree cover in each transect was calculated as the average tree cover in a radius of $90 \mathrm{~m}$ around the starting point of each transect.

Soil nutrients and soil texture were obtained for most transects $(n=147)$ from previous surveys (<http://ppbio. inpa.gov.br $>$ ). For soil measurements, five soil samples were collected at a depth of $5 \mathrm{~cm}$ at $50 \mathrm{~m}$ intervals along each transect, pooled, and analyzed for texture and soil chemistry. Before analysis, soil samples were cleaned of roots, air-dried, and sieved through a $2 \mathrm{~mm}$ sieve. Soil texture analyses were conducted at the Soil Laboratory of the Agronomy Dept at INPA and chemical analyses at the Soil Laboratory of the Brazilian Enterprise of Research of Livestock and Agriculture, Manaus (Embrapa 1997).

Transects with in situ measurements of soil nutrient and texture were distributed in central, northern, and southern Amazonia. To include transects with missing soil data (25\% of transects), we inputed missing soil data into transects by randomly selecting observed values from other transects. Although this procedure adds noise to the data, and potentially reduces the power of the tests, it does not increase type I error rates. To confirm that data inputation did not affect our ability to detect an association between soil variables and termite community, all analyses were re-run considering only transects in which soil data were available.

To investigate the association of riverine barriers with termite community structure, we assigned each transect to one of five biogeographic regions from which four were previously defined by Ribas et al. (2011): 1) Guiana - west northern of Negro river and west of Branco river; 2) Guiana - east - northern of Negro river and east of Branco river; 3) Negro - southern of Rio Negro and northern of the Amazon river; 4) Inambari - southern of the Amazon river and western of the Madeira river; and 5) Rondonia southern of the Amazon river and eastern of the Madeira river. These regions are bounded by the major rivers in Amazonia and have been associated with the composition (Pomara et al. 2014, Dias-Terceiro et al. 2015) and diversification (Ribas et al. 2011, Boubli et al. 2015) of several vertebrate taxa. The vector representing the five biogeographic regions was included as a categorical predictor variable in regression (ANCOVA) and RDA models (see Data analysis section for details).

In Amazonia, variation in environmental conditions is usually more strongly associated with geographic distance than the presence of rivers (Pomara et al. 2014). The weak association between riverine barriers and the environment usually allows separating the effects of riverine barriers and edaphic conditions on species distribution (Higgins et al. 2011, Pomara et al. 2014).

\section{Data analysis}

Because the number of sections sampled in each transect ranged from five to 12 , we rarefied the termite data on those transects in which more than five sections were sampled. For each termite species in each transect, we calculated the species abundance and probability of occurrence (presence) expected in a random draw of five sections per transect. We provide details on rarefaction calculations in Supplementary material Appendix 1, Text A2. Therefore, the sampling effort per transect may differ from other studies focusing on the taxonomic representation of termites in a single area, or in which fewer transects were sampled (Jones and Eggleton 2000, Davies et al. 2003).

Termite species richness per transect was calculated as the average species richness that would be achieved by sampling five sections per transect. To quantify the turnover in termite species composition, we calculated the Bray-Curtis dissimilarity index between all pairs of transects based on the matrix of average species occurrences per transect $(=$ the probability of sampling a given species in a transect when sampling five sections). Virtually the same results were obtained performing the same analyses using only five randomly selected sections per transect. Additionally, the Bray-Curtis dissimilarity index between pairs of transects was decomposed into the balanced variation and abundance components (Baselga 2013). Different ecological processes generate patterns of species abundance and species replacements (balanced component). Abundance gradients can be associated with 
differences in productivity between areas, or dispersive processes over limited geographical ranges. In contrast, neutral processes and ecological sorting over large areas should only be associated with the balanced component of beta diversity (Svenning et al. 2011).

We performed multiple linear regression analyses using species richness as response variable, and a distance-based redundancy analysis (db-RDA) using the Bray-Curtis dissimilarity index as a response variable representing termite species composition. Similar results were obtained by using a db-RDA analysis on the abundance balanced component of the Bray-Curtis index of species dissimilarities (Supplementary material Appendix 1, Fig. A2), or a RDA analysis on the Hellinger transformed species occurrence data (results not shown). RDA analyses using the Hellinger transformation have relatively high statistical power to detect associations of species composition and environmental variables, and is commonly used (Legendre and Gallagher 2001).

To separate the effects of environmental variables and riverine barriers on termite species richness and composition, we included the vector representing the biogeographic region of transects as a covariate into the regression and db-RDA models. We used variance partitioning to determine the amount of variance in termite species richness and species composition uniquely associated with environmental variables and with the biogeographic region of transects.

Similar to other constrained ordination methods, RDA analysis can be problematic due to arch effects (Palmer 1993). As an alternative to db-RDA, we performed a Non-Metric Multidimensional Scaling (NMDS) with two dimensions on the Bray-Curtis dissimilarity matrix. We then used the scores from NMDS as response variables in multiple regression analyses. The results from the regressions using the NMDS scores were very similar to the results from the db-RDA analysis.

Altitude was correlated with mean annual temperature $(\mathrm{r}=0.49 ; \mathrm{p}<0.001)$ and mean annual precipitation $(\mathrm{r}=0.56 ; \mathrm{p}<0.001)$ and was not included in regression and RDA models. $\mathrm{Mg}^{2+}$ was correlated with $\mathrm{K}^{+}(\mathrm{r}=0.56$; $\mathrm{p}<0.001)$ and $\mathrm{Ca}^{2+}(\mathrm{r}=0.50 ; \mathrm{p}<0.001)$. The concentration of these nutrients was combined, and we used the total concentration of exchangeable cations in the soil as a response variable (see Tuomisto et al. 2014 for a similar approach). The remaining variables were weakly correlated to each other $(\mathrm{r}<0.4)$ and were used as independent predictor variables. Because species usually show a stronger response to the increase in soil nutrients at low soil nutrient content (Tuomisto et al. 2014), P and soil cations were log transformed prior to the analyses.

\section{Controlling for spatial autocorrelation and spatial structure on termite community}

Over large areas, ecological communities show strong spatial autocorrelation (Koenig 1999): areas close to each other exhibit similar composition of species. Spatial autocorrelation in biological communities can result from neutral processes, such as random dispersal, and deterministic processes, such as the species responses to spatially structured environmental variables (Legendre and Gauthier 2014). If all relevant environmental data are included, spatial statistical analyses can be used to disentangle the effects of environmental variables on species distribution from species spatial distribution not caused by the environment. When controlling for spatial autocorrelation, spatial statistical analyses also correct for type I error rates which can be inflated by the lack of independence of samples (Peres-Neto and Legendre 2010). Because we were interested in the spatial distribution of species caused both by environmental variables and by historical processes that may include dispersal, we included Moran Eigenvector Maps (MEMs) based on the geographical location of the sampled transects as explanatory variables in our models (Peres-Neto and Legendre 2010; see detailed information on MEMs construction in Supplementary material Appendix 1, Text A3).

The MEM analysis generated 197 vectors representing spatial autocorrelation from local to broad scales which could be used individually as covariates in regression models. To reduce the number of spatial predictors in our models, we selected only those MEMs with significant spatial structure as suggested by Dray et al. (2012) and Griffith and PeresNeto (2006). We determined the significance of MEMs by comparing the observed Moran's I index of each MEM with expectations based on a Monte Carlo randomization (Dray et al. 2006, 2012, Griffith and Peres-Neto 2006). Additionally, we selected only those MEMs with high explanatory power for a given response variable by performing a forward selection of MEMs based on the adjusted $R^{2}$ values (Peres-Neto and Legendre 2010). Because different vectors can have distinct explanatory power for each measure of the termite community, forward selection was conducted independently for termite species richness and the Bray-Curtis dissimilarity index representing changes in termite species composition. Finally, we divided MEMs into vectors representing local and broad scale spatial autocorrelation. Local and broad scale MEMs were defined by having small or large associated eigenvalues (Dray et al. 2006, 2012, Griffith and Peres-Neto 2006).

The selected MEMs were incorporated as covariates in regression and $\mathrm{db}-\mathrm{RDA}$ analyses along with environmental variables and the biogeographic positioning of transects. We used variance partitioning to separate: 1 ) variation in species distribution explained uniquely by the environment (E), 2) variation in species distribution explained uniquely by spatial autocorrelation, possibly caused by neutral processes $(S), 3)$ variation in species distribution associated uniquely with the biogeographic positioning of transects $(B G), 4)$ variation explained jointly by the environment, by spatial autocorrelation, and by biogeographic region $(E+S$, $\mathrm{BG}+\mathrm{S}, \mathrm{E}+\mathrm{BG}$, and $\mathrm{E}+\mathrm{S}+\mathrm{BG}$ ), and 5) unexplained or residual variation in species distribution $(\mathrm{R})$. Spatial variance was further partitioned into variance explained by local and broad scale spatial autocorrelation.

To partition the variance into broad and local-scale components, we first fitted regression and RDA models using only broad-scale or local-scale MEMs as predictor variables. The residuals from these models were then regressed against environmental variables and MEMs that were not included in the initial models. Broad-scale MEMs represent all possible broad-scale spatial structure present in 
the data (Dray et al. 2012). Therefore, when the effect of broad-scale MEMs is removed from response variables, only local-scale variation (e.g. within grids and between neighboring transects) should remain. This residual variation can be explained by environmental variables with local variation or local scale spatial autocorrelation, or remain unexplained (R). The advantage of using variance partitioning instead of conducting analyses at the metacommunity and grid scales separately is that MEMs represent spatial scales continuously from local to broad scales. Moreover, because MEMs already control for spatial autocorrelation, type I error rates are not inflated (Peres-Neto and Legendre 2010).

In addition to community-level analyses, we performed pairwise comparisons of congeneric species to determine if their range of distributions were bounded by rivers. For these analyses, eight termite genera were selected: Syntermes, Cornitermes, Neocapritermes, Termes, Cylindrotermes, Anoplotermes, Ruptitermes, and Rhinotermes. All selected genera have multiple species occurring in at least two sampling grids each. These genera represent the two families found (Termitidae and Rhinotermitidae) and multiple subfamilies, and include species with a wide range of nesting and feeding habits, such as soil-feeding (e.g. Anoplotermes) and woodfeeding termites (e.g. Cylindrotermes), that could potentially differ in the capacity to disperse across rivers. Species occurring in only one sampling grid were not included in pairwise comparisons.

Geographic barriers to dispersal associated with allopatric speciation can cause congeneric species to be spatially segregated (Ribas et al. 2011). To test if the co-occurrence of congeneric species was lower than expected, we counted the number of sampling grids in which individual pairs of congeneric species co-occur. The mean co-occurrence within genera (MC) was then calculated, and MC compared against expectations from a null model. The null model randomly assigned species into genera while maintaining the number of species per genus and the occurrence of individual species in grids constant. The randomization was repeated 999 times $(\mathrm{N})$ and MC recalculated in each randomization. P-values were calculated as the frequency with which the co-occurrence of congeneric species in the null model $\left(\mathrm{MC}_{\text {null }}\right)$ was lower or equal to the observed co-occurrence $\left(\mathrm{Mc}_{\mathrm{obs}}\right.$; one-tail test):

$$
p=\frac{\sum_{i=1}^{N}\left(M C_{n u l l \mid i} \leq M C_{o b s}\right)+1}{N+1}
$$

The null model used here is analogous to those commonly used for phylogenetic analyses of species co-occurrence in which species labels are reshuffled in a phylogeny (Webb 2000). Therefore, using a taxonomic tree with two levels would produce similar results.

We conducted all analyses in the $\mathrm{R}$ program ( $\mathrm{R}$ Development Core Team). Altitude and tree cover data were extracted from raster files using the raster package (Hijmans and Etten 2013). We used the spdep (Bivand 2013) and spacemakeR (Dray 2013) packages to create the connectivity matrix between grids using a Gabriel graph, and to calculate MEMs. db-RDA, RDA, NMDS, and variance partitioning analyses were performed by using $\mathrm{R}$ code modified from Dray et al. (2012), and functions from the vegan package (Oksanen et al. 2008). Moran's I and bootstrap functions to perform significance tests on MEMs were created specifically for this study, and are available at $<\mathrm{https} / / \mathrm{dx}$.doi. org/10.6084/m9.figshare.1319582.v10>. We provide a step-by-step document explaining community level analyses conducted in R (Supplementary material Appendix 2). We made all termite data publicly available at $<$ https://dx.doi. org $/ 10.6084 / \mathrm{m} 9$. figshare.1319582.v10> under Creative Commons - BY license (free to use and distribute). Links for downloading termite data and $\mathrm{R}$ functions are also provided in Supplementary material Appendix 2.

\section{Results}

We found a total of 271 termite species or morphospecies in 4389 colonies. Termite species richness per transect was higher in the relatively colder and dryer areas of southern (Brazilian shield; $S=13.4 \pm 3.5$ ) and northern Amazonia (Guiana shield; $S=11.8 \pm 3.1$ ) than in central Amazonia $(S=9.2 \pm 2.8$; ANOVA test: $\mathrm{p}<0.01)$.

Termite species richness and species composition had a strong spatial structure at broad geographic scales $\left(R_{r i c h}^{2}=0.47 ; R_{d b R D A s p a c e: b r o a d}^{2}=0.23\right)$, but were not spatially structured at local geographic scales $\left(\mathrm{R}_{\text {rich }}^{2}=0.09\right.$; $R_{d b R D A s p a c e: l o c a l}^{2}<0.01$ ), as quantified by regressions and $\mathrm{db}$ RDA analyses of termite species richness and composition against broad- and local-scale MEMs. After we removed broad scale spatial autocorrelation, most of the remaining variation in termite species richness $(93 \%)$ and species composition (94\%) was variation within the sampling grids.

When all variables were included in the regression model, twenty two percent of the variation in termite species richness could be explained either by spatial variation at broad geographic scales (broad scale MEMs) or by environmental variables with broad scale spatial autocorrelation (adjusted $\mathrm{R}^{2}$ values; Fig. 2A). Although termite species richness was higher in areas with high concentration of soil cations $(r=0.25)$ and low mean annual temperature $(r=-0.40)$ and precipitation $(\mathrm{r}=-0.28)$, only precipitation was associated with a reduction in termite species richness when spatial autocorrelation was controlled for (Supplementary material Appendix 1, Table A1). Despite the association of environmental variables with termite species richness, $27 \%$ of the variation in species richness could be explained only by spatial predictors associated with geographic distance (MEMs), but not accounted for by the environment or by biogeographic regions delimited by major rivers (Fig. 2A).

The composition of termite species quantified by RDA and NMDS analyses was similar in adjacent regions separated by major rivers (Inambari and Guiana (east) in Fig. 3A). In contrast, areas separated by large geographic distances had distinct species composition (Guiana (west), Negro, and Rondonia regions in Fig. 3A). Most of the broad-scale variation in termite species composition could be explained either by spatial predictors or differences in environmental conditions between regions (Fig. 2B, Fig. 3B). Termite species composition was associated with mean annual temperature $\left(\mathrm{r}_{\mathrm{CAP1}}=-0.27 ; \mathrm{r}_{\mathrm{CAP} 2}=0.48\right)$, precipitation $\left(\mathrm{r}_{\mathrm{CAP1}}=-0.68\right.$; $\left.r_{C A P 2}=0.19\right)$, clay content $\left(r_{C A P 1}=-0.29 ; r_{C A P 2}=-0.43\right)$, and $\mathrm{P}\left(\mathrm{r}_{\mathrm{CAP} 1}=0.25, \mathrm{r}_{\mathrm{CAP} 2}=0.30\right.$; Fig. 3B $)$. However, only 
(A)

\section{Species richness}

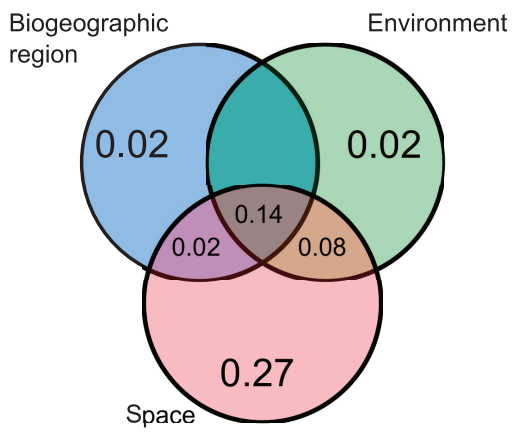

(B)

\section{Species composition}

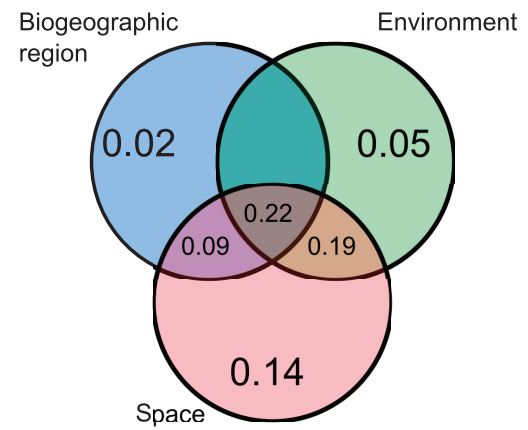

Values $<0$ not shown

Figure 2. Variance in termite species richness (A) and composition (B) explained $\left(R^{2}\right)$ by biogeographic region, environmental variables, and spatial predictors. Species composition was measured as two axes of non-metric multidimensional scaling (NMDS) analysis using the Bray-Curtis dissimilarity index. To represent riverine barriers, each sampled transect was assigned to one of five biogeographic regions delimited by the major rivers in the Amazonian region. Spatial predictors were represented by Moran eigenvector maps based on the geographical distance between transects. db-RDA and non-metric multidimensional scaling (NMDS) analyses provided very similar results.

precipitation, clay content, and P were significantly associated with termite species composition when spatial variation was partialed out in dbRDA analyses (Fig. 3D). Spatial predictors (broad-scale MEMs) alone explained more variation in termite species composition than did environmental predictors alone $\left(R_{d b R D A s p a c e \mid e n v+\text { riv }}^{2}=0.04 ; \quad R_{d b R D A e n v \mid \text { space }+ \text { riv }}^{2}=0.02\right)$. The presence of major rivers alone explained less variation in termite species composition than environmental variables or spatial predictors alone $\left(R_{d b R D A r i v \mid e n v+\text { space }}^{2}<0.01\right)$. Results from NMDS analyses provided similar results to dbRDA analyses $\left(R_{N M D S \text { space } e n v+\text { riv }}^{2}=0.14 ; R^{2}{ }_{N M D S e n v \mid \text { space }+ \text { riv }}=0.05\right.$; $R_{N M D S \text { riv } \mid \text { space }+ \text { env }}^{2}=0.02$; Fig. 2B; Supplementary material Appendix 1, Fig. A3).

The turnover in termite species composition with soil clay content and $\mathrm{P}$ was associated with the differential response of soil and wood-feeding termites to these gradients. The species richness of soil-feeding termites was higher in areas of high soil clay content $(b=0.56 ; \mathrm{p}<0.001)$, whereas the species richness of wood-feeding termites was higher in areas of low soil clay content $(b=-0.26 ; \mathrm{p}=0.01)$ and high $\mathrm{P}(b=0.44 ; \mathrm{p}<0.001)$. The species richness of soil-feeding termites was also higher in areas with high concentration of soil bases $(b=0.66 ; \mathrm{p}<0.001)$, and differed in southern $(S=7.8 \pm 2.7)$, northern $(S=5.8 \pm 3.36)$, and central Amazonia $(S=3.94 \pm 2.3$; ANOVA test: $\mathrm{p}<0.01)$.

When termite species were analyzed individually, no termite species had a range of distribution clearly bounded by the major rivers included in our study. Moreover, there was no evidence that congeneric species co-occur less than expected by chance $(\mathrm{p}=0.88)$.

\section{Discussion}

In spite of a rich literature on the drivers of species distribution in Amazonia, most previous studies have been of vertebrates and plants, and most have been conducted in the more topographically complex areas of western Amazonia (Gascon et al. 2000, Tuomisto et al. 2003, Higgins et al. 2011, Kristiansen et al. 2012, Pomara et al. 2014). Those studies have shown that the distribution of plants is mostly associated with soil chemistry (Tuomisto et al. 2003, Higgins et al. 2011), whereas vertebrate distribution can be affected by barriers to dispersal, particularly rivers (Pomara et al. 2014). In our study of termite assemblages in central, northern, and southern Amazonia, soil clay content was strongly associated with changes in species composition at local scales (Fig. 3D). However, at broad spatial scales, temperature, precipitation, soil bases, and isolation by distance were also strong predictors of species richness and composition (Fig. 3B).

Broad-scale climatic associations are often found for terrestrial taxa (Hawkins et al. 2003, ter Steege et al. 2010, Cancello et al. 2014). However, the correlations for Amazonian termites are the reverse of the typical: termite species richness was higher in relatively colder and dryer areas of southern and northern Amazonia. In exposed habitats such as savannas, surface temperatures of soil, leaves, and other unshaded microhabitats can be very high (Kaspari 1993), which can suppress termite activity (Smith and Rust 1994). Termite richness is also lower in areas of high seasonal precipitation and areas that are periodically flooded (Dawes-Gromadzki and Spain 2003). The lack of association of termite species composition with climate at local spatial scales could result from the low resolution of measures of temperature and precipitation at these scales (Bedia et al. 2013). Despite the possible direct effects of climate on termite species distribution, climatic variables had low variation in our study area, and the negative association of termites with temperature and precipitation likely resulted from the effect of other variables correlated with climate.

The relatively colder and drier areas with high termite species richness in our study coincide with the Guiana and 
(A)

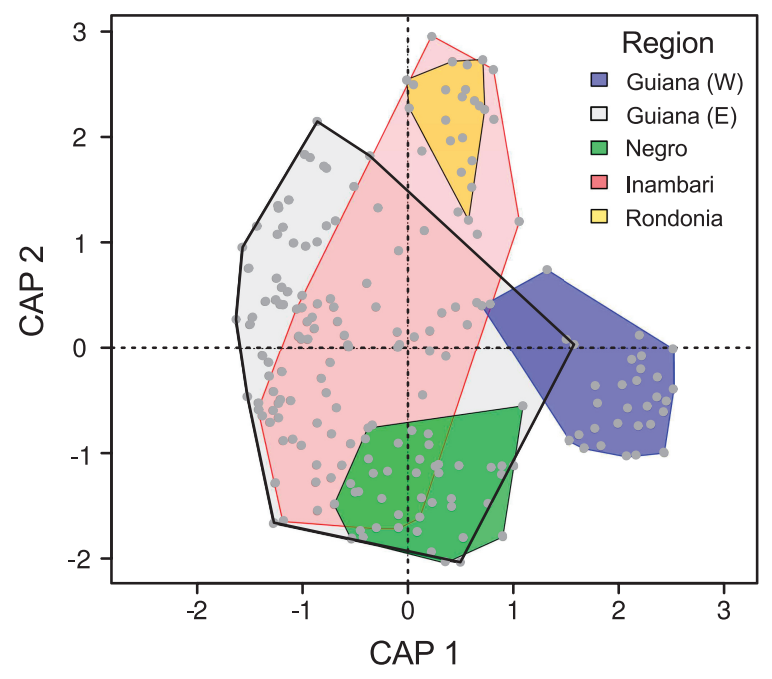

(C)

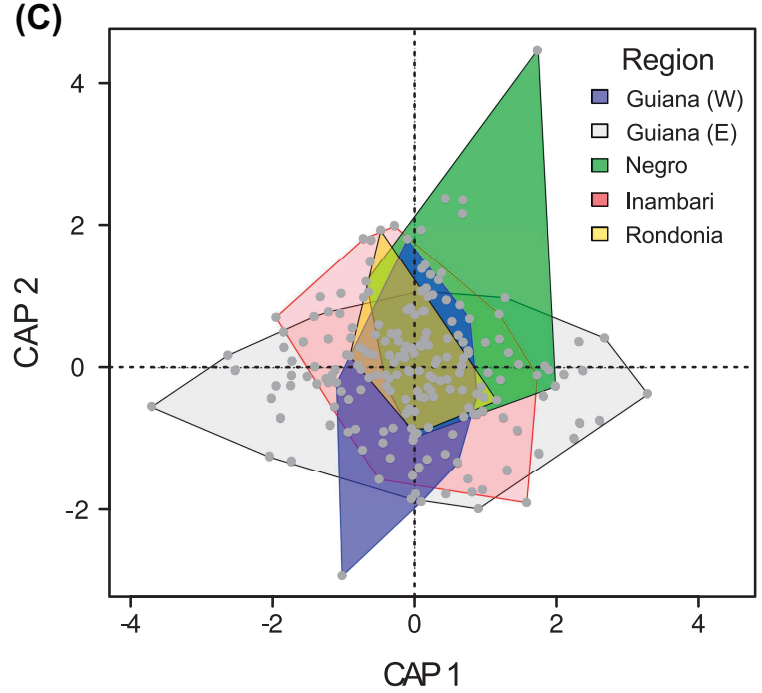

(B)

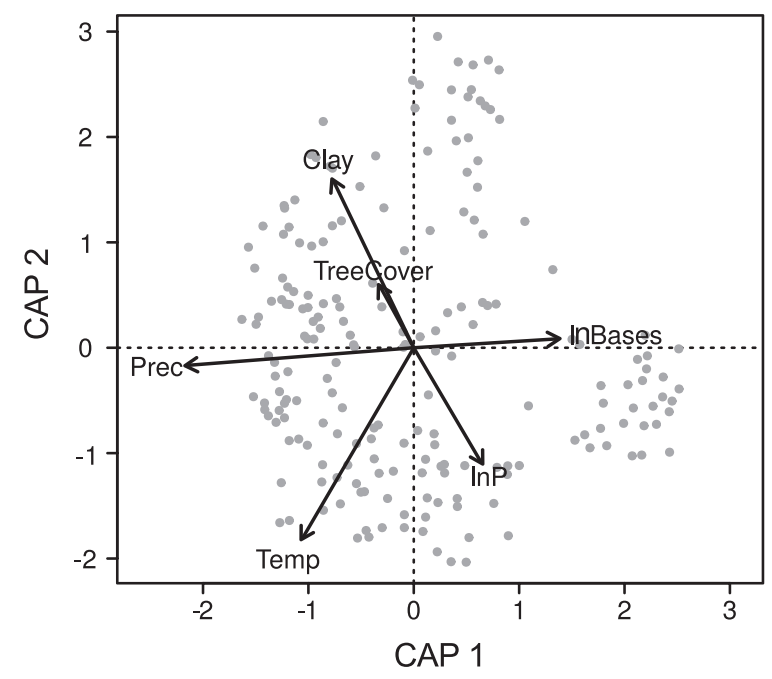

(D)

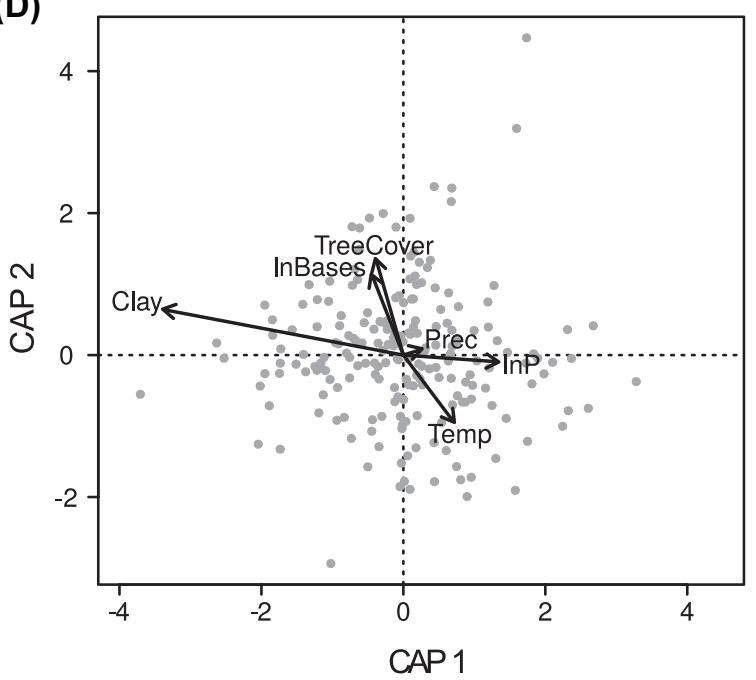

Figure 3. Biplot based on a distance-based redundancy analysis (db-RDA) representing the association of termite species composition (response variable) and environmental variables (predictor variables) before (A-B) and after $(\mathrm{C}-\mathrm{D})$ the removal of spatial structure on termite data. Termite species composition was measured using the Bray-Curtis dissimilarity index (summarized in PCoA axes in db-RDA analysis). Polygons in (A) and (C) represent clusters of transects delimited by the major rivers in Amazonia. Temp: mean annual temperature; Prec: mean annual precipitation. Spatial predictors (197 MEMs) are not shown in (A) and (B) for clarity.

Brazilian shields in the north and south. These ancient geological formations have higher content of soil bases than more recent sedimentary formations of central Amazonia (Quesada et al. 2011). In our study, termite species richness and composition varied with soil bases, especially for soil-feeding termites. Soil-feeding termite species (e.g. Anoplotermes spp.) were much more common in areas with high soil bases, whereas other termite species (e.g. Cylindrotermes spp. and Neocapritermes braziliensis) occurred slightly more in areas of low soil bases.

Previous termite studies also found a higher incidence of soil-feeding termites in northern Amazonia (Davies 2002, Davies et al. 2003) than in central Amazonia (Ackerman et al. 2009). Similar changes in species composition along soil gradients have also been observed for plants in western Amazonia (Higgins et al. 2011) and central Amazonia (Lehtonen et al. 2015). In western Amazonia, plants exhibit sharp discontinuities in species composition along edaphic gradients. These discontinuities are associated with changes in soil types and cannot be explained by differences in climate or by the presence of geographical barriers to dispersal (Higgins et al. 2011). Although the number of sampling grids in our study was too small to capture abrupt discontinuities, it is likely that both climate and soil type affected the distribution of termite species (Davies 2002, Davies et al. 2003, Cancello et al. 2014). Moreover, more than $27 \%$ of the variation in termite species richness and composition could be explained only by the geographic separation between areas, and not by soil type or climate.

The distinct composition of species in distant areas can result from unmeasured environmental variables or reflect dispersal limitation and historical effects (Legendre and Gauthier 2014). Spatially structured environments are often 
associated with changes in species composition (Tuomisto et al. 2003), and separating the effects of niche and neutral processes can be difficult. The climatic (Cancello et al. 2014) and edaphic (Davies et al. 2003) variables included in our study have been associated with the distribution of termites in other regions. However, the variation in climatic variables was much smaller in our study region, and other unmeasured variables, such as vegetation composition (Roisin and Leponce 2004), could be associated with the distribution of termites in Amazonia. Although unmeasured environmental variables might explain some of the spatial patterns found, neutral processes, such as random dispersal coupled with diversification, are likely to be more important when environmental heterogeneity is not relevant (McGill et al. 2006). In addition to the effect of environmental variables on species composition, our results suggest that historical processes and dispersal limitation also contribute to the distribution of species in the Amazonian forest.

In Amazonia, large rivers are important geographic barriers for dispersal of many vertebrate taxa (Pomara et al. 2014), and may have contributed to the diversification of Amazonian birds (Ribas et al. 2011), frogs (Funk et al. 2007), and primates (Boubli et al. 2015). In contrast, rivers are not associated with changes in species composition of plants (Higgins et al. 2011, Kristiansen et al. 2012, Pomara et al. 2014). In our study, differences in termite species composition were strongly correlated with geographic distance per se, but the composition of species was not distinct across major rivers (Fig. 3). Indeed, we have often observed large termite swarms flying over major rivers (Dambros unpubl.), which might even facilitate dispersal in areas of densely covered forest. Collectively, our results and those of other studies suggest that rivers may not be important barriers to dispersal for plant and invertebrate taxa with high dispersal capacity.

Although random dispersal might have shaped termite communities at broad geographic scales in Amazonia, we cannot rule out an important effect of past climate or geological events on contemporary termite distribution. Termite evolutionary history is complex, and include several events of long-distance dispersal followed by in situ diversification (Bourguignon et al. 2014). Areas in pre-Cambrian formations of the Guiana and Brazilian shields to the north and south could have played an important role in termite diversification and species assembly. The mixture of historical factors, climate, soil, and distance effects operating at broad and local spatial scales have contributed to the complex patterns of species richness and composition in Amazonia.

Acknowledgements - We acknowledge the editor Andrés Baselga for his comments which greatly improved the manuscript. We also thank William E. Magnusson and Elizabeth Franklin for their valuable ideas during the development of this project. CSD was supported by Coordenação de Aperfeiçoamento de Pessoal de Nível Superior (CAPES/BEX 536610-0). Finantial support for the project was provided by Fundação de Amparo à Pesquisa do Estado do Amazonas (FAPEAM) and Conselho Nacional de Desenvolvimento Científico e Tecnológico (CNPQ 474867/2011-0). Logistic support and previously collected data were provided by the Program for Biodiversity Research (PPBio).

\section{References}

Ackerman, I. L. et al. 2009. Termite (Insecta: Isoptera) species composition in a primary rain forest and agroforests in central Amazonia. - Biotropica 41: 226-233.

Baselga, A. 2013. Separating the two components of abundancebased dissimilarity: balanced changes in abundance vs. abundance gradients. - Methods Ecol. Evol. 4: 552-557.

Bedia, J. et al. 2013. Dangers of using global bioclimatic datasets for ecological niche modeling. Limitations for future climate projections. - Global Planet. Change 107: 1-12.

Bignell, D. E. et al. (eds) 2011. Biology of termites: a modern synthesis. - Springer.

Bivand, R. 2013. spdep: spatial dependence: weighting schemes, statistics and models. - <http://cran.r-project.org/web/ packages/spdep/index.html $>$.

Boubli, J. P. et al. 2015. Spatial and temporal patterns of diversification on the Amazon: a test of the riverine hypothesis for all diurnal primates of Rio Negro and Rio Branco in Brazil. - Mol. Phylogenet. Evol. 82: 400-412.

Bourguignon, T. et al. 2014. The evolutionary history of termites as inferred from 66 mitochondrial genomes. - Mol. Biol. Evol. 32: 406-421.

Cadotte, M. 2006. Dispersal and species diversity: a meta-analysis. - Am. Nat. 167: 913-924.

Cancello, E. M. et al. 2014. Latitudinal variation in termite species richness and abundance along the Brazilian Atlantic forest hotspot. - Biotropica 46: 441-450.

Constantino, R. 1999. Chave ilustrada para identificação dos gêneros de cupins (Insecta: Isoptera) que ocorrem no Brasil. - Papéis Avulsos de Zool. 40: 387-448.

Costa, F. R. C. 2006. Mesoscale gradients of herb richness and abundance in central Amazonia. - Biotropica 38: 711-717.

Costa, F. R. C. et al. 2009. Gradients within gradients: the mesoscale distribution patterns of palms in a central Amazonian forest. - J. Veg. Sci. 20: 69-78.

Davies, R. 2002. Feeding group responses of a Neotropical termite assemblage to rain forest fragmentation. - Oecologia 133: 233-242.

Davies, R. G. et al. 2003. Environmental and spatial influences upon species composition of a termite assemblage across neotropical forest islands. - J. Trop. Ecol. 19: 509-524.

Dawes-Gromadzki, T. and Spain, A. 2003. Seasonal patterns in the activity and species richness of surface-foraging termites (Isoptera) at paper baits in a tropical Australian savanna. - J. Trop. Ecol. 19: 449-456.

Dias-Terceiro, R. G. et al. 2015. A matter of scale: historical and environmental factors structure anuran assemblages from the upper Madeira River, Amazonia. - Biotropica 47: 259-266.

Donovan, S. E. et al. 2001. Gut content analysis and a new feeding group classification of termites. - Ecol. Entomol. 26: 356-366.

Dray, S. 2013. spacemakeR: spatial modelling. $-\mathrm{R}$ package ver. 0.0-5/r113, <http://R-Forge.R-project.org/projects/sedar/ >.

Dray, S. et al. 2006. Spatial modelling: a comprehensive framework for principal coordinate analysis of neighbour matrices (PCNM). - Ecol. Model. 196: 483-493.

Dray, S. et al. 2012. Community ecology in the age of multivariate multiscale spatial analysis. - Ecol. Monogr. 82: 257-275.

Eiserhardt, W. L. et al. 2011. Geographical ecology of the palms (Arecaceae): determinants of diversity and distributions across spatial scales. - Ann. Bot. 108: 1391-1416.

Embrapa 1997. Manual de métodos de análises de solo. - Embrapa, Rio de Janeiro, Brazil.

Fittkau, E. J. and Klinge, H. 1973. On biomass and trophic structure of the central Amazonian rain forest ecosystem. - Biotropica 5: 2-14. 
Funk, W. C. et al. 2007. Tests of biogeographic hypotheses for diversification in the Amazonian forest frog, Physalaemus petersi. - Mol. Phylogenet. Evol. 44: 825-837.

Gascon, C. et al. 2000. Riverine barriers and the geographic distribution of Amazonian species. - Proc. Natl Acad. Sci. USA 97: 13672-13677.

Griffith, D. A. and Peres-Neto, P. R. 2006. Spatial modeling in ecology: the flexibility of eigenfunction spatial analyses. - Ecology 87: 2603-2613.

Hawkins, B. A. et al. 2003. Energy, water, and broad-scale geographic patterns of species richness. - Ecology 84: 3105-3117.

Higgins, M. A. et al. 2011. Geological control of floristic composition in Amazonian forests. - J. Biogeogr. 38: 2136-2149.

Hijmans, R. J. and van Etten, J. 2013. raster: geographic data analysis and modeling. - <http://cran.r-project.org/web/ packages/raster/>.

Hijmans, R. J. et al. 2005. Very high resolution interpolated climate surfaces for global land areas. - Int. J. Climatol. 25: 1965-1978.

Hubbell, S. P. 2005. Neutral theory in community ecology and the hypothesis of functional equivalence. - Funct. Ecol. 19: 166-172.

Hurtt, G. C. and Pacala, S. W. 1995. The consequences of recruitment limitation: reconciling chance, history and competitive differences between plants. - J. Theor. Biol. 176: 1-12.

Jones, D. T. and Eggleton, P. 2000. Sampling termite assemblages in tropical forests: testing a rapid biodiversity assessment protocol. - J. Appl. Ecol. 37: 191-203.

Kaspari, M. 1993. Body size and microclimate use in Neotropical granivorous ants. - Oecologia 96: 500-507.

Koenig, W. D. 1999. Spatial autocorrelation of ecological phenomena. - Trends Ecol. Evol. 14: 22-26.

Kristiansen, T. et al. 2012. Environment versus dispersal in the assembly of western Amazonian palm communities. - J. Biogeogr. 39: 1318-1332.

Legendre, P. and Gallagher, E. D. 2001. Ecologically meaningful transformations for ordination of species data. - Oecologia 129: 271-280.

Legendre, P. and Gauthier, O. 2014. Statistical methods for temporal and space-time analysis of community composition data. - Proc. R. Soc. B 281: 20132728.

Lehtonen, S. et al. 2015. Phylogenetic relatedness within Neotropical fern communities increases with soil fertility. - Global Ecol. Biogeogr. 24: 695-705.

Leibold, M. A. et al. 2004. The metacommunity concept: a framework for multi-scale community ecology. - Ecol. Lett. 7: 601-613.

Magnusson, W. E. et al. 2005. RAPELD: a modification of the Gentry method for biodiversity surveys in long-term ecological research sites. - Biota Neotrop. 5: 19-24.

McGill, B. J. et al. 2006. Empirical evaluation of neutral theory. - Ecology 87: 1411-1423.

Menin, M. et al. 2007. Topographic and edaphic effects on the distribution of terrestrially reproducing anurans in central Amazonia: mesoscale spatial patterns. - J. Trop. Ecol. 23: 539.

NSF OpenTopography Facility 2013. Shuttle Radar Topography Mission (SRTM) 90 m. - NSF OpenTopography Facility.

Oksanen, J. et al. 2008. Vegan: community ecology package. - R package ver. 1.13-1.

Palmer, M. W. 1993. Putting things in even better order: the advantages of canonical correspondence analysis. - Ecology 74: $2215-2230$

Supplementary material (Appendix ECOG-02663 at <www. ecography.org/appendix/ecog-02663>). Appendix 1-2.
Peel, M. C. et al. 2007. Updated world map of the KöppenGeiger climate classification. - Hydrol. Earth Syst. Sci. 11: 1633-1644.

Penz, C. et al. 2015. Butterfly dispersal across Amazonia and its implication for biogeography. - Ecography 38: 410-418.

Peres-Neto, P. R. and Legendre, P. 2010. Estimating and controlling for spatial structure in the study of ecological communities. - Global Ecol. Biogeogr. 19: 174-184.

Pomara, L. Y. et al. 2014. Avian species composition across the Amazon River: the roles of dispersal limitation and environmental heterogeneity. - J. Biogeogr. 41: 784-796.

Quesada, C. A. et al. 2011. Soils of Amazonia with particular reference to the RAINFOR sites. - Biogeosciences 8: $1415-1440$.

Ribas, C. C. et al. 2011. A palaeobiogeographic model for biotic diversification within Amazonia over the past three million years. - Proc. R. Soc. B 279: 681-689.

Roisin, Y. and Leponce, M. 2004. Characterizing termite assemblages in fragmented forests: a test case in the Argentinian Chaco. - Austral Ecol. 29: 637-646.

Sexton, J. O. et al. 2013. Global, 30-m resolution continuous fields of tree cover: Landsat-based rescaling of MODIS vegetation continuous fields with lidar-based estimates of error. - Int. J. Digital Earth 6: 427-448.

Smith, J. L. and Rust, M. K. 1994. Temperature preferences of the western subterranean termite, Reticulitermes hesperus Banks. - J. Arid Environ. 28: 313-323.

Svenning, J.-C. et al. 2011. Climate, history and neutrality as drivers of mammal beta diversity in Europe: insights from multiscale deconstruction. - J. Anim. Ecol. 80: 393-402.

Tarli, V. D. et al. 2014. Multiple environmental controls on cockroach assemblage structure in a tropical rain forest. - Biotropica 46: 598-607.

ter Steege, H. et al. 2010. Contribution of current and historical processes to patterns of tree diversity and composition of the Amazon. - In: Hoorn, C. et al. (eds), Amazonia, landscape and species evolution: a look into the past. Blackwell, pp. 349-359.

Thompson, R. and Townsend, C. 2006. A truce with neutral theory: local deterministic factors, species traits and dispersal limitation together determine patterns of diversity in stream invertebrates. - J. Anim. Ecol. 75: 476-484.

Tuomisto, H. et al. 2003. Dispersal, environment, and floristic variation of western Amazonian forests. - Science 299: 241-244.

Tuomisto, H. et al. 2014. Species richness and diversity along edaphic and climatic gradients in Amazonia. - Ecography 37: $1034-1046$.

USGS 2008. GLSDEM, 90 m scenes GLSDEM_p230r062_z21, GLSDEM_p231r062_z20, GLSDEM_p231r063_z20, GLS DEM_p231r62z20, GLSDEM_p232r058_z20, GLSDEM_ p232r059_z20, GLSDEM_p232r061_z20, and GLSDEM p233r066_z20. - Global Land Cover Facility, Univ. of Maryland, College Park, MD.

Webb, C. O. 2000. Exploring the phylogenetic structure of ecological communities: an example for rain forest trees. - Am. Nat. 156: 145-155.

Wilfert, L. et al. 2006. Differentiation between populations of a termite in eastern Africa: implications for biogeography. - J. Biogeogr. 33: 1993-2000. 